\title{
STUDY OF MICROSATELLITES IN THE RUSSIAN BREEDS OF TURKEY
}

\section{V.I. FISININ1, M.I. SELIONOVA², L.A. SHINKARENKO3, N.G. SHCHERBAKOVA ${ }^{3}$, L.V. KONONOVA ${ }^{2}$}

\author{
${ }^{1}$ Federal Scientific Center All-Russian Research and Technological Poultry Institute RAS, Federal Agency of Scientific \\ Organizations, 10, ul. Ptitsegradskaya, Sergiev Posad, Moscow Province, 141315 Russia; \\ ${ }^{2}$ All-Russian Research Institute for Sheep and Goat Breeding, Federal Agency of Scientific Organizations, 15, Zoo- \\ technicheskii per., Stavropol, 355017 Russia, e-mail m_selin@mail.ru (corresponding author); \\ ${ }^{3}$ Breeding and Genetic Center of North Caucasian Zonal Experimental Station for Poultry Breeding, Federal Agency of \\ Scientific Organizations, s. Obilnoye, Georgievskii Region, Stavropol Krai, 357812 Russia \\ ORCID:
}

Fisinin V.I. orcid.org/0000-0003-0081-6336 Selionova M.I. orcid.org/0000-0002-9501-8080

Kononova L.V. orcid.org/0000-0003-3812-9099

The authors declare no conflict of interests

Received December 13, 2016

\section{Abstract}

Currently, in the total volume of poultry meat production turkey (Meleagris gallopavo) meat takes the second place in the world. According to the analytical agency (Global Reach Consulting, Russia), this segment has grown more than 8 times over the last 10 years. Positive dynamics is also observed in Russia, i.e. a $34.9 \%$ increase has been achieved in 2015, mainly due to the use of modern genetic approaches and highly efficient technologies. The high competition in the market of the world's poultry genetic material defines the importance of monitoring its origin and genetic consolidation. It is known that one of the most informative methods for studying genetic biodiversity of different species in animals and birds is the analysis of microsatellite loci. The estimation in microsatellite loci in turkey breeds and commercial lines, bred in USA, Turkey, Hungary and other countries has allowed us to establish genetic profiles of breeds, their differentiation, similarities and differences. However, till now the study of microsatellite polymorphism in the Russian breeds of turkeys was not conducted. The aim of this work was to study polymorphism and genetic differentiation on microsatellite loci of turkeys' breeds of the Russian selection. The work was carried out at the North Caucasian Zonal Experimental Station for Poultry Breeding using the turkey breeds of the Russian selection maintained in the Breeding and Genetic Center of North Caucasian Zonal Experimental Station for Poultry Breeding. MLVA (multiple locus variable, number tandem repeats analysis) genotyping was performed on 12 VNTR loci (MNT9-MNT20). Blood samples were taken from turkeys of seven breeds: broad-breasted White $(n=12)$, North Caucasian Bronze $(n=12)$, North Caucasian White $(n=9)$, North Caucasian Silvery $(n=15)$, Moscow White $(n=12)$, Tikhoretskaya Black $(n=10)$, Uzbek Buff $(n=8)$. DNA was isolated using guanidine thiocyanate. The quality of DNA samples was determined spectrophotometrically. The detection of PCR amplification products was carried out by the presence of specific bands on the electrophoregram in the agarose gel. To quantify the discriminating ability of the typing method, we used the Hunter-Gaston index. For grouping, the pairwise unweighted clustering with arithmetic averaging (UPGMA) was performed, the dendrogram was constructed using a computer program START-2. It is established that 3 loci (MNT11, MNT15, MNT17) of 12 investigated VNTR loci were monomorphic, and 6 loci (MNT9, MNT10, MNT12, MNT14, MNT19 and MNT20) had two alleles each. For MNT16, 3 alleles were revealed, and only MNT13 and MNT18 produced 4 alleles each. Twenty one of 26 identified alleles have not been previously described or deposited in specialized international databases that specifies in originality of the investigated Russian turkey breeds. Phylogenetic analysis of genetic distances allowed us to allocate two unequal clusters - I and II. The cluster I is formed by a part of broad-breasted White genotypes and from all genotypes of Uzbek Buff breed. The cluster II is formed by two large C and D groups: C group is formed by genotypes of North Caucasian Bronze, North Caucasian White and broad-breasted White breeds, and D group is formed by genotypes of Tikhoretskaya Black, North Caucasian Silvery and Moscow White breeds. Features of genetic differentiation in turkey breeds of the Russian selection are due to their history and the participation of the gene pool of sertain breeds in creation of others. Allelic variants identified by us in the investigated loci for the first time allow further researches on genetic differentiation of turkey breeds of the Russian and foreign selection. 

ic diversity

Currently, in the total volume of poultry meat production turkey (Meleagris gallopavo) meat takes the second place in the world. According to the analytical agency Global Reach Consulting (GRC, Russia), this segment has grown more than 8 times over the last 10 years. Positive dynamics is also observed in Russia: a $34.9 \%$ increase has been achieved in 2015, mainly due to the use of modern genetic approaches and highly efficient technologies. The high competition in the market of the world's poultry genetic material defines the importance of monitoring its origin and genetic consolidation.

Microsatellite loci analysis is one of the most informative methods for studying genetic biodiversity of different species in animals and birds [1-3]. It is known that microsatellites, SSR (simple sequence repeat) or STR (short tandem repeat), are the tandem repeats with a length of 2 to 4 , sometimes up to 6 pairs of nucleotides in non-coding regions of the genome. The priority of their use in DNA diagnostics is due to a relatively uniform distribution on chromosomes and a wide variety. Polymorphism of microsatellite repeats is so high that it makes it possible to distinguish chromosomes during family analysis, tracing their transmission in generations, and also attributing a biological sample to a species, breed, and population [4].

Since the data on the populations genetic structure are extremely important for the rational use of the genetic resources of farm animals and poultry, the Food and Agriculture Organization of the United Nations (FAO) carried out the Global Project for the Measurement of Domestic Animal Genetic Diversity (MoDAD) [5, 6]. Genotyping from 6 to 50 breeds of the same species was performed with the help of 30 microsatellite loci. An example of the successful project approbation was the results of studying the genetic diversity of microsatellite markers in more than 50 populations of chickens [7, 8]. Despite the fact that a significant number of microsatellite loci in turkeys are identified and mapped [9-11], a unified microsatellite panel for M. gallopavo has not been proposed to date [12].

Scholarly papers on genetic diversity in turkeys demonstrated the possibility of using the microsatellite panel recommended by FAO for hens to evaluate it. So, when describing the genetic profile of the Nero d'Italia, Brianzolo and Colli Euganei breeds, raised in Turkey, 22 out of 31 chicken markers were informative. 63 common alleles were identified for the three breeds, according to them. At the same time, 10 markers were examined using multiplex panels (Multiplex Master Mix 1 - ADL0268, ADL0278, LEI0094, MCW0216, MCW0248; Master Mix 2 - MCW0034, MCW0069, MCW0081, MCW0222, MCW0295), and 12 loci (ADL0112, LEI0192, LEI0234, MCW0014, MCW0016, MCW0037, MCW0067, MCW0098, MCW0103, MCW0111, MCW0165, MCW0183) were studied separately in single PCR. No PCR products were detected for 9 markers (LEI0166, MCW0020, MCW0078, MCW0080, MCW0104, MCW0123, MCW0248, MCW0284 and MCW0330) [13].

K. Reed et al. [14] performed the most ambitious study of the chicken microsatellite loci informativeness for estimation of the genetic characteristics of the turkey. They used 520 microsatellite chicken markers and obtained amplification products with turkey DNA only for 280 markers (54\%). For the further analysis, 57 loci were selected, in 20 of which a low allelic polymorphism was established, an average of 1.4 alleles per locus. The authors concluded that about $20 \%$ of microsatellite chicken markers are informative when studying genetic biodiversity in turkey populations [14]. Genetic profiles of two turkey breeds (BIG6 and BIG10) were constructed using eight microsatellite 
chicken (Gallus gallus) markers, MCW0111, MCW0067, LEI0104, MCW0123, MCW0081, MCW0069, MCW0104 and MCW0183. The polymorphism of 7 loci out of 8 loci studied was established, which allowed the authors to conclude that the microsatellite loci of $G$. gallus are informative for characterizing the gene pool of M. gallopavo [3].

The study of multiple locus variable (number tandem repeats) analysis, MLVA, was performed on turkey breeds in several countries. Thus, E.K. Latch et al. [15] surveyed populations of the Eastern wild turkey (M. gallopavo silvestris) and domestic turkey (M. gallopavo), bred in Turkey, for 7 microsatellite loci. The number of alleles per locus varied from 5 to 15 , while the average heterozygosity was high for almost all loci. Domestic turkey was characterized by a much smaller number of alleles per locus with a low overall heterozygosity compared to the Eastern wild turkeys [15]. In their study, K. Reed et al. [16] discovered eight new microsatellite loci in turkeys.

D. Kamara et al. [17] examined the genetic relationships between commercial and non-commercial turkey breeds (Narra-gansett, Bourbon Red, Blue Slate, Spanish Black and Royal Palm) from the gene pool of the Virginia College farm, using 10 microsatellite loci (RHT0009, RHT0011, RHT0024, RHT0095, RHT0131, RHT0216, RHT0294, TUM16, TUM20, ADL0023). Phylogenetic analysis revealed that the Narra-gansett, Bourbon Red and Blue Slate breeds had a greater genetic similarity with commercial breeds than the Spanish Black and Royal Palm [17)]. Similar results for these breeds were obtained using three marker systems: RAPD (randomly amplified polymorphic DNA), microsatellite and SNP (single nucleotide polymorphism) [18].

In a joint study, US and Turkey scientists, while identifying microsatellite loci that were convenient and informative for the study of the turkey genome, designed primers for 164 genomic DNA regions containing microsatellites, based on a data library. The authors conclude that 154 detected genetic markers are quite acceptable for analysis, but further research is required to develop an informative panel [19].

S. Kusza et al. (20), studying populations of turkeys of Hungarian Bronze and broad-breasted White breeds using 15 microsatellite loci, found that the first population was highly polymorphic (the average number of alleles per locus was 3.20). The obtained data and the genetic analysis by M. Nei made it possible to clearly differentiate the studied populations.

For the most complete description of genetic diversity of turkey breeds and lines bred in Turkey, their genome was sequenced [21]. It is established that all modern Turkish commercial lines have a common origin and are derived from wild populations. At the same time, wild turkeys are characterized by higher heterozygosity compared to commercial lines. The authors concluded that the turkey genome is much less diverse than that of other farm animals and poultry.

By now, the study of the genetic profile of turkey Russian breeds, including microsatellite loci, has not been carried out, which determines the relevance of our study.

For the first time, we performed MLVA to genotype Russian turkey breeds for 12 microsatellite (MNT9-MNT20) VNTR (variable number of tandem repeats) loci. The genetic uniqueness of the studied breeds is established: out of the 24 identified alleles, 18 have not been previously described and annotated in specialized international databases. Phylogenetic analysis based on genetic distances revealed grouping of the part of broad-breasted White genotypes and all genotypes of the Uzbek Buff breed in one cluster, while genotypes of the North Caucasus Bronze, North Caucasian White, broad-breasted White, Tikho- 
retsky Black, North Caucasian Silvery and Moscow White breeds formed another cluster. The obtained data showed that the patterns of genetic diversification of Russian turkey breeds are due to the history of their origin and the participation of the gene pool of some breeds in the creation of others.

The purpose of this work was to study polymorphism and genetic diversification of microsatellite loci in Russian turkey breeds.

Techniques. The study was carried out on breeds raised in the Selectiongenetic center of the North Caucasian Zone Experimental Station for Poultry Farming (Stavropol Krai). To determine the genetic diversity against 12 VNTRloci, blood samples were taken from seven turkey breeds: broad-breasted White $(n=12)$, North Caucasian Bronze $(n=12)$, North Caucasian White $(n=9)$, North Caucasian Sylver $(n=15)$, Moscow White $(n=12)$, Tikhoretsky Black $(n$ $=10)$, Uzbek Buff $(n=8)$

The DNA was extracted by guanidine thiocyanate method according to the protocol to the AmpliPrime DNA-sorb-AM commercial set (InterLabService, Russia). The purity of the DNA samples was evaluated spectrophotometrically $\left(\mathrm{A}_{260 / 280}\right)$.

For the MLVA genotyping, 12 VNTR loci (MNT9-MNT20) [22] were selected. PCR was carried out in a final volume of a $20 \mu \mathrm{l}$ mixture containing following amounts of reagents per reaction: $1 \mu$ forward primer $(F)$ and $1 \mu l$ reverse primer (R) (FKUZ StavNIPChI Rospotrebnadzor, Russia), $2 \mu \mathrm{l}$ dNTPs, $4 \mu \mathrm{l}$ RNA eluent, $10 \mu \mathrm{l}$ PCR-mixture-2red solution (InterLabService, Russia) and 2 $\mu$ LNA from the blood sample. All reactions were carried out in the following mode: $15 \mathrm{~min}$ at $95{ }^{\circ} \mathrm{C}$ (initial denaturation); $30 \mathrm{~s}$ at $95{ }^{\circ} \mathrm{C}, 30 \mathrm{~s}$ at $58{ }^{\circ} \mathrm{C}$ (for the loci MNT10, MNT11, MNT20 the temperature was $\left.56^{\circ} \mathrm{C}\right), 30 \mathrm{~s}$ at $72{ }^{\circ} \mathrm{C}$ (35 cycles); $5 \mathrm{~min}$ at $72{ }^{\circ} \mathrm{C}$ (final elongation).

PCR amplification products were detected by the presence of specific lines during electrophoretic separation in a $1.5 \%$ agarose gel. The exact size of the alleles of the identified markers for all VNTR loci in each test sample was determined using an automated microcapillary electrophoresis station Experion System (Bio-Rad Laboratories, USA).

To evaluate the discriminatory ability of the genotyping protocol, the Hunter Gaston Discriminatory Index (HGDI) was used [23]. Cluster analysis was performed using the Unweighted Pair Group Method with Arithmetic Mean (UPGMA), and START 2 [24] software was used to construct dendrograms.

Results. The Selection-genetic center of the North Caucasian Zone Experimental Station for Poultry (Stavropol Territory) is the only enterprise in Russia that creates new breeds and crosses, and ensures the preservation of the turkey gene pool.

1. Primers used to amplify 12 VNTR loci in Russian turkey breeds (North Caucasian Zone Experimental Station for Poultry, Stavropol Krai)

\begin{tabular}{l|ll}
\hline \multirow{2}{*}{ VNTR locus } & \multicolumn{2}{c}{ Nucleotide sequence of primer $\left(5^{\prime} \rightarrow 3^{\prime}\right)$} \\
\cline { 2 - 3 } MNT9 & \multicolumn{1}{c}{ forward $(\mathrm{F})$} & \multicolumn{1}{c}{ reverse $(\mathrm{R})$} \\
MNT10 & TGGGAGTGGAAAGGTGAAAG & \multicolumn{1}{c}{ TTCTCCTCAGCTCAGCAACC } \\
MNT11 & TTCCCAGTGCACTACCTGAAC & TGAACAGTGATTCCACTGAAGC \\
MNT12 & TTTCTGACACAGGTACAAGGAAAC & GCCCTCGAGTATTAGCCACTC \\
MNT13 & AGGTGTTTTGGGCAGTCTC & TGCAAGCACCATCTGCTAAG \\
MNT14 & TTAGGGGATGCTGAACTGTG & GCGTAATTGGTGCTTTCTCC \\
MNT15 & AAACAGAACAACCTCAAGGACAG & GAATTGGGTTGCATTTGAG \\
MNT16 & TTGTTGCTGTTGTTTTGTG & TTTCTGTGCCTAAGCTTAATGTG \\
MNT17 & TGTTTGCCTGCAATAAGCTG & GCACCCTCCCACTGACTG \\
MNT18 & GGAGCACCCAGCTCAAAG & GAGTAATACCAAGGAAAATGTGC \\
MNT19 & GCAGGCACAGAGAGCTACG & CCAATGTTGAAGCAGGTGAG \\
MNT20 & GCAGGAGGCTCTGAGCTATG & TTATACGGAAGGCGGTTGAG \\
\hline
\end{tabular}



in Table 1.

Sequences of the primers used to amplify the 12 MLVA loci are shown

A

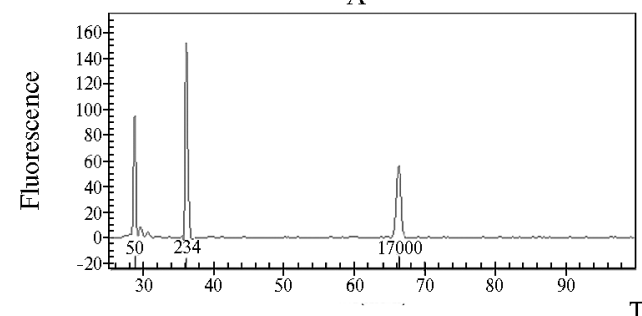

B

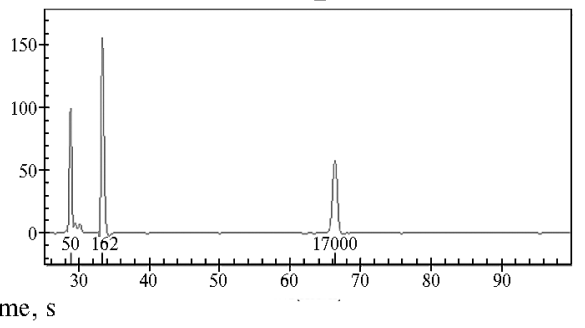

Fig. 1. Examples of determining the allele size of VNTR loci found in Russian turkey breeds, based on microcapillary electrophoresis of PCR products: A - previously not described allele 234 bp (locus MNT16, sample No. 140, Tikhoretsky Black breed), B - previously not described allele $162 \mathrm{bp}$ (locus MNT18, sample No. 107, Moscow White breed); 50 and 1700 - peaks corresponding to the standards of $50 \mathrm{bp}$ and 17,000 bp (Experion System, Bio-Rad Laboratories, USA).

The carried out research has allowed us to reveal some features of variable VNTR loci in the studied Russian turkey breeds (Table 2).

2. Variability of VNTR loci in the studied Russian turkey breeds (North Caucasian Zone Experimental Station for Poultry, Stavropol Krai)

\begin{tabular}{l|cll}
\hline \multicolumn{1}{c}{ Locus } & Number of alleles & Size of an allele, bp \\
\hline MNT9 & 2 & $164^{*}, 168$ \\
MNT10 & 2 & $67^{*}, 78^{*}$ \\
MNT11 & Invariable & $90^{*}$ \\
MNT12 & 2 & $121^{*}, 145$ \\
MNT13 & 4 & $183^{*}, 185^{*}, 187^{*}, 235^{*}$ \\
MNT14 & 2 & $177,181^{*}$ \\
MNT15 & Invariable & 188 \\
MNT16 & 3 & $219^{*}, 226^{*}, 234^{*}$ \\
MNT17 & Invariable & $181^{*}$ \\
MNT18 & 4 & $158,159^{*}, 161^{*}, 162^{*}$ \\
MNT19 & 2 & $224^{*}, 250^{*}$ \\
MNT20 & 2 & $192^{*}, 195^{*}$ \\
N o t e. The asterisk denotes allelic variants of VNTR loci \\
not described earlier.
\end{tabular}

Out of the 12 examined loci, MNT11, MNT15 and MNT17 were monomorphic. In six loci (MNT9, MNT10, MNT12, MNT14, MNT19, MNT 20), two alleles were detected, three alleles were detected in the MNT16 locus, and two loci, MNT13 and MNT18, showed four alleles each. Consequently, the average number of alleles per locus was 2 . The obtained data to some extent confirms the conclusions of other scientists that turkeys' genome is less polymorphic and more conservative at microsatellite loci compared to other farm animals [21, 25].

At the same time, the data obtained by us make it possible to draw a conclusion about the genetic originality of the studied Russian turkey breeds. Thus, out of the 26 detected alleles of VNTR loci, 21 have not been previously described in other breeds and were not annotated in specialized international databases. Identified variants of alleles made it possible to divide the individuals of the studied breeds into 14 types against 12 variable VNTR loci, on the basis of which a dendrogram of genetic distances was constructed, reflecting phylogenetic relationships (Fig. 2).

Two unequal clusters, I and II, emerged on the dendrogram. The first cluster grouped a part of the genotypes of the broad-breasted White breed (branch A) and all genotypes of the Uzbek Buff breed (branch B). The combination of these breeds in one cluster seems quite reasonable, since the Uzbek Buff breed was developed by crossing of local Uzbek Bronze turkeys with broadbreasted White ones.

The second cluster, in turn, was formed by two large groups C and D. Group C included the genotypes of the North Caucasian Bronze, North Caucasian White and broad-breasted White. The similar location of the North Caucasian Bronze and North Caucasian White breeds in subcluster C1 (branches C1.1 and $\mathrm{C} 1.2$, respectively) is explained by the use of the gene pool of one breed in 
107 - ST-10 (168,78,90,145,235,177,188,234,181,162,250,192) 106 - ST-10 $(168,78,90,145,235,177,188,234,181,162,250,192)$ 120 - ST-10 $(168,78,90,145,235,177,188,234,181,162,250,192)$

119 - ST-10 $(168,78,90,145,235,177,188,234,181,162,250,192)$

118 - ST-10 (168,78,90,145,235,177,188,234,181,162,250,192)

104 - ST-9 (168,78,90,145,235,177,188,226,181,162,250,192)

103 - ST-9 $(168,78,90,145,235,177,188,226,181,162,250,192)$

102 - ST-9 $(168,78,90,145,235,177,188,226,181,162,250,192)$

101 - ST-9 $(168,78,90,145,235,177,188,226,181,162,250,192$ 100 - ST-9 $(168,78,90,145,235,177,188,226,181,162,250,192)$

99 - ST-9 $(168,78,90,145,235,177,188,226,181,162,250,192)$

98 - ST-9 $(168,78,90,145,235,177,188,226,181,162,250,192)$

97 ST $9(168,78,90,145,235,177,188,226,181,162,250,192)$

96 - ST-9 $(168,78,90,145,235,177,188,226,181,162,250,192)$

96 - ST-9 $(168,78,90,145,235,177,188,226,181,162,250,192)$

95 - ST-9 $(168,78,90,145,235,177,188,226,181,162,250,192)$
94 - ST-9 $(168,78,90,145,235,177,188,226,181,162,250,192)$

93 - ST-9 $(168,78,90,145,235,177,188,226,181,162,250,192)$

92 - ST-9 $(168,78,90,145,235,177,188,226,181,162,250,192)$

91 - ST $9(168,78,90,145,235,177,188,226,181,162,250,192)$

(

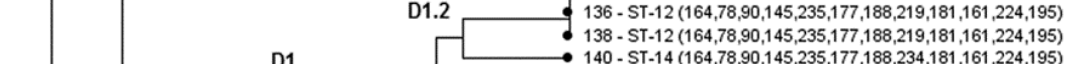

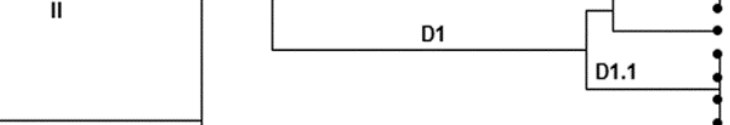

- ST-13 $(168,78,90,145,235,177,188,219,181,161,224,195)$ 142 - ST $13(168,78,90,145,235,177,188,219,181,161,224,195)$ (141 - ST-13(168,78,90,145,235,177,188,219,181,161,224,195)

(141 139 - ST-13(168,78,90,145,235,177,188,219,181,161,224,195) 53 - ST-3 $(168,67,90,121,185,177,188,234,181,162,224,195)$ \begin{tabular}{|lll} 
& &
\end{tabular}

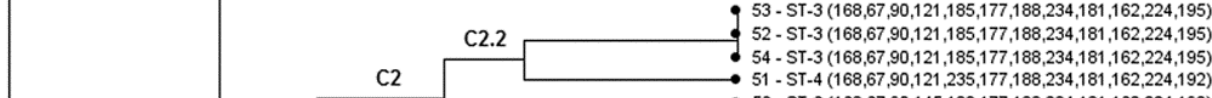
I 56 - ST-6 $(168,67,90,145,183,177,188,234,181,162,224,192)$ 55 - ST- $6(168,67,90,145,183,177,188,234,181,162,224,192)$

50 - ST-6 $(168,67,90,145,183,177,188,234,181,162,224,192)$

49 - ST-6 $(168,67,90,145,183,177,188,234,181,162,224,192)$ - 76 - ST-8 $(168,67,90,145,235,181,188,226,181,162,224,195)$ 67 - ST-8 $(168,67,90,145,235,181,188,226,181,162,224,195)$ 66 - ST-8 $(168,67,90,145,235,181,188,226,181,162,224,195)$ 65 - ST $8(168,67,90,145,235,181,188,226,181,162,224,195)$ 64 - ST- $8(168,67,90,145,235,181,188,226,181,162,224,195)$

63 - ST- $8(168,67,90,145,235,181,188,226,181,162,224,195)$

C1.2 62 - ST-8 $(168,67,90,145,235,181,188,226,181,162,224,195)$ 61 - ST-8 $(168,67,90,145,235,181,188,226,181,162,224,195)$ 90 - ST-8 $(168,67,90,145,235,181,188,226,181,162,224,195)$ 89 - ST-8 $(168,67,90,145,235,181,188,226,181,162,224,195)$ 88 - ST $8(168,67,90,145,235,181,188,226,181,162,224,195)$

77 ST $8(168,67,90,145,235,181,188,226,181,162,224,195)$ C1.1 85 - ST-7 $(168,67,90,145,185,181,188,226,181,162,224,195)$ 84 - ST-7 $(168,67,90,145,185,181,188,226,181,162,224,195)$ 83 - ST-7 $(168,67,90,145,185,181,188,226,181,162,224,195)$

75 - ST-7 $(168,67,90,145,185,181,188,226,181,162,224,195)$ 68 - ST-1 $(164,67,90,121,187,181,188,234,181,159,224,195)$ 29 - ST $1(164,07,90,121,187,181,188,234,181,159,224,195)$ 29 - ST-1 $(164,67,90,121,187,181,188,234,181,159,224,195)$ 28 - ST-1 (164,67,90,121,187,181,188,234,181,159,224,195) 27 - ST-1 $(164,67,90,121,187,181,188,234,181,159,224,195)$ 158 - ST-1 $(164,67,90,121,187,181,188,234,181,159,224,195)$ 157 - ST-1 $(164,67,90,121,187,181,188,234,181,159,224,195)$ 156 - ST-1 $(164,67,90,121,187,181,188,234,181,159,224,195)$ 155 - ST-1 $(164,67,90,121,187,181,188,234,181,159,224,195)$

B 154 - ST-1 $(164,67,90,121,187,181,188,234,181,159,224,195)$ 153 - ST-1 $(164,67,90,121,187,181,188,234,181,159,224,195)$ 152 - ST-1 $(164,67,90,121,187,181,188,234,181,159,224,195)$ 151 - ST-1 $(164,67,90,121,187,181,188,234,181,159,224,195)$ 111 - ST-1 $(164,67,90,121,187,181,188,234,181,159,224,195)$ 109 - ST-1 $(164,67,90,121,187,181,188,234,181,159,224,195)$ 78 - ST-1 (164,67,90,121,187,181,188,234,181,159,224,195) 72 ST $1(164,67,00,121,187,181,188,234,181,159,224,195)$

Fig. 2. Dendrogram of genetic distances between the Russian turkey breeds based on 12 variable VNTR loci (MLVA): I and II - clusters; A, B - groups; C1, C2, D1, D2 - subclusters, C1.1, C1.2, C2.1, C2.2, D1.1, D1.2, D2.1, D2.2 - branches of subclusters (see the text for rescription).

Sample numbers by breed: broad-breasted White $-27-30,49-56(n=12)$; North Caucasian Bronze - 61-69, 75-77 $(n=12)$; North Caucasian White - 71, 72, 78, 83-85, 88-90 $(n=9)$; North Caucasian Sylver - 91-105 $(n=15)$; Moscow White - 106-111, 114-120 $(n=12)$; Tikhoretsky Black - 137-142, 145, 146, $150(n=10)$; Uzbek Buff $-151-158(n=8)$; St 1-14 -14 genotypes found in the studied turkey breeds against 12 microsatellite loci (the numbers of the alleles corresponding to the genotypes St 1-14 are indicated in parentheses) (North Caucasian Zone Experimental Station for Poultry, Stavropol Krai). 
the creation of another one. Thus, the first domestic turkey breed, the North Caucasian Bronze, was bred in the 1950s and 1960s by a prolonged use of the Bronze and broad-breasted Bronze gene pool breeds during the breeding of local turkeys. The second domestic breed, the North Caucasian White, was created in the 1970s and 1980s by crossing the North Caucasian Bronze turkeys with males of broad-breasted White breed of English origin. Genotypes of broad-breasted White breed formed their own subcluster C2, branches C2.1 and C2.2, were located very close to each other, which confirms belonging to the same breed and indicates its high genetic consolidation.

It is known that the broad-breasted White breed of turkeys is one of the oldest in the world. It was imported from Britain to Russia in the early 1960s. In 1980, the North Caucasian Zone Experimental Station for Poultry received four Hidon crossing lines, A, B, C, D, from the Netherlands. Using two lines, B and $\mathrm{D}$, parent forms have been obtained, pure breeding of which is being maintained to date. Group D (see Fig. 2) also consisted of two subgroups: subgroup D1 was formed solely by genotypes of the Tikhoretsky Black breed which divided into branches D1.1 and D1.2. In the D2 subgroup, the D2.1 branch was formed only by the North Caucasian Silvery breed, and the D.2.2 branch included genotypes of the Moscow White breed.

A certain genetic isolation of these breeds is explained by the history of their creation. Thus, the modern North Caucasian Silvery breed, approved in 2008, was created based on the gene pool of the Uzbek Buff and broad-breasted White breeds. To increase the reproduction and improvement of meat types, a repeated introductory crossing of hybrids with maternal males of broad-breasted White breed (line O4) was carried out. During the next step, the population was improved by breeding in itself. The Tikhoretsky Black breed, formerly known as the Krasnodar Black, was created in the years 1950-1960 in the Krasnodar Krai during prolonged mass breeding of local turkeys with black plumage. The Moscow White breed was derived during the same period based on a complex highperformance crossing of local white turkeys with Dutch White and Beltsville Small White turkeys. In subsequent generations, the crossbred females were improved by crossing with the Beltsville Small White males and further the desired genotypes were bred in themselves.

The obtained results allow us to conclude that turkeys of the same breed, as a rule, had the same MLVA12 type and clustered as a single subgroup on the dendrogram.

Calculations showed that the discriminating ability of our analysis of 12 variable VNTR loci (MLVA12 method) was satisfactory. According to common practice, the typing method is considered acceptable if the Hunter-Gaston index is $\geq 0.9$. In our study, the value of this index (HGDI $=0.9$ ) corresponded with the acceptable values

Thus, as a result of the analysis of a phylogenetic tree constructed on the basis of genotyping native turkey breeds at the North Caucasian Zone Experimental Station for Poultry for 12 variable VNTR loci (MLVA12 types), the groups formed were characterized by different degree of discrimination. Turkeys of the same breed usually have the same MLVA12 type and clustered together on a dendrogram. In the studied breeds, the average number of alleles per locus was 2, which agrees with the notion that the turkey genome is more conservative for microsatellite loci. The discriminating ability of the used MLVA12 method was satisfactory $($ HGDI $=0.9)$. The alleles of the studied loci which we identified for the first time (a total of 21 allelic variants) allow us to continue the study of genetic differentiation in turkeys of Russian and foreign breeding. For an in-depth analysis of genetic characteristics of turkey 
breeds, it is advisable to use a comprehensive approach using additional methods of genetic analysis, such as SNP, MLST (multilocus sequence typing) and Sanger sequencing.

\section{REFEREN CES}

1. Put man A.I., C a r b o ne I. Challenges in analysis and interpretation of microsatellite data for population genetic studies. Ecology Evolution, 2014, 4(22): 4399-4428 (doi: 10.1002/ece3.1305).

2. Novgorodova I.P., Volkova V.V., Glad yr E.A., S e 1 i o nova M.I., R a s tova rov E.I., F is in in V.I., Z i novi e va N.A. Dostizheniya nauki i tekhniki APK, 2011, 10: 66-67 (in Russ.).

3. Fi s i n i n V.I., G 1 a d y r E.A., Volkova V.V., S e vas t'y a nova A.A., Zi nov'ev a N.A. Problemy biologii produktivnykh zhivotnykh, 2011, 1: 68-72 (in Russ.)..

4. J a r n e P., Lag o d a P.J.L. Microsatellites, from molecules to populations and back. Trends in Ecology \& Evolution, 1996, 11(10): 424-429 (doi: 10.1016/0169-5347(96)10049-5).

5. We ige nd S., Ro m a n ov M.N. The world watch list for domestic animal diversity in the context of conservation and utilisation of poultry biodiversity. World's Poultry Science Journal, 2002, 58(4): 411-430 (doi: 10.1079/WPS20020031).

6. Groeneveld L.F., Lenstra J.A., Eding H., Toro M.A., Scherf B., Pi1ling D., Negrini R., Finlay E.K., Jianlin H., Groeneveld E., Weigend S. Genetic diversity in farm animals: a review. Animal Genetics, 2010, 41(1): 6-31 (doi: 10.1111/j.1365-2052.2010.02038.x).

7. Solle r M., We igend S., Ro ma nov M.N., D e k ke rs J.C.M., La mo n t S.J. Strategies to assess structural variation in the chicken genome and its associations with biodiversity and biological performance. Poultry Science, 2006, 85(12): 2061-2078 (doi: 10.1093/ps/85.12.2061).

8. Wilkinson S., Wi e ner P., T everson D., H al e y C.S., Hocking P.M. Characterization of the genetic diversity, structure and admixture of British chicken breeds. Animal Genetics, 2012, 43(5): 552-563 (doi: 10.1111/j.1365-2052.2011.02296.x).

9. Reed K.M., Roberts M.C., Murtaugh J., B e attie C.W., Alexande r L.J. Eight new dinucleotide microsatellite loci in turkey (Meleagris gallopavo). Animal Genetics, 2000, 31(2): 140 (doi: 10.1046/j.1365-2052.2000.00571.x).

10. Burt D.W., Morrice D.R., S ewalem A., S mith J., Paton I.R., S mith E.J., B e nt ley J., Hocking P.M. Preliminary linkage map of the turkey (Meleagris gallopavo) based on microsatellite markers. Animal Genetics, 2003, 34(6): 399-409 (doi: 10.1046/j.13652052.2003.01033.x).

11. Chaves L.D., Knut so n T.P., Krueth S.B., Re ed K.M. Using the chicken genome sequence in the development and mapping of genetic markers in the turkey (Meleagris gallopavo). Animal Genetics, 2006, 37(2): 130-138 (doi: 10.1111/j.1365-2052.2005.01396.x).

12. G holizade h M., Mi a $\mathrm{nj}$ i G.R. Use of microsatellite markers in poultry research. International Journal of Poultry Science, 2007, 6(2): 145-153 (doi: 10.3923/ijps.2007.145.153).

13. Colombo E., Strillacci G., Cozzi M.C., Madeddu M., Mangiagalli M.G., M o s c a F. Feasibility study on the FAO chicken microsatellite panel to assess genetic variability in the turkey (Meleagris gallopavo). Italian Journal of Animal Science, 2014, 13(4): 887-890 (doi: 10.4081/ijas.2014.3334).

14. R e ed K., M e ndoza K.M., B e a t t i e C.W. Comparative analysis of microsatellite loci in chicken and turkey. Animal Genetics, 2000, 43: 796-802 (doi: 10.1139/g00-045).

15. Lat $\mathrm{ch}$ E.K., S mith E.J., Rhodes O.E. Isolation and characterization of microsatellite loci in wild and domestic turkeys (Meleagris gallopavo). Molecular Ecology Notes, 2002, 2: 176178 (doi: 10.1046/j.1471-8286.2002.00183.x).

16. Reed K., Roberts M.C., Murtaugh J., B e attie C.W., Alexande r L.J. Eight new dinucleotide loci in turkey (Melagris gallopavo). Animal Genetics, 2000, 31: 140-157 (doi: 10.1046/j.1365-2052.2000.00571.x).

17. Ka mara D., Gyenai K.B., Geng T., Ha m made H. Microsatellite marker-based genetic analysis of relatedness between commercial and heritage turkeys (Meleagris gallopavo). Poultry Science, 2007, 86(1): 46-49 (doi: 10.1093/ps/86.1.46).

18. S mith E.J., Geng T., Long E., Pierson F.W., Sponenberg D.P., Larson C., G og a 1 R. Molecular analysis of the relatedness of five domesticated turkey strains. Biochemical Genetics, 2005, 43(1-2): 35-47 (doi: 10.1007/s10528-005-1065-5).

19. Knuts o n T.P., C haves L.D., H a 11 M.K., R e d K.M. One hundred fifty-four genetic markers for the turkey (Meleagris gallopavo). Genome, 2004, 47(6):1015-28 (doi: 10.1139/g04-076).

20. Kusza S., Mihyk S., Czeglédi L., Jávor A., Árnyasi M. Testing the breeding strategy of Hungarian Bronze turkey strains for maintaining genetic diversity with microsatellites. Archiv Tierzucht, 2011, 54(4): 419-429.

21. Aslam M., Bastiaansen J., Elferink M., Megens J. Crooijmans R., 
B lo mberg L., Fle is cher R., Van Tassell C., Sonstegard T., Schroed e r S., G ro e n e n M., L o ng J. Whole genome SNP discovery and analysis of genetic diversity in Turkey (Meleagris gallopavo). BMC Genomics, 2012, 13: 391-404 (doi: 10.1186/14712164-13-391).

22. R e e d K., Chave s L.D., R ow e J.A. Twelve new turkey microsatellite loci. Poultry Science, 2002, 81: 1789-1791 (doi: 10.1093/ps/81.12.1789).

23. Hunter P.R., Gaston M.A. Numerical index of the discriminatory ability of typing systems: an application of Simpson's index of diversity. Journal of Clinical Microbiology, 1988, 26(11): 2465-2466 (PubMed ID: 3069867).

24. START 2. Available http://pubmlst.org/software/analysis/start. No date.

25. Guan X., Silva P., Gyenai K.B., Xu J., Geng T., Tu Z., Samuels D.C., $\mathrm{S} \mathrm{m}$ i t h E.J. The mitochondrial genome sequence and molecular phylogeny of the turkey, Meleagris gallopavo. Animal Genetics, 2009, 40(2): 134-141 (doi: 10.1111/j.1365-2052.2008.01810.x). 